\title{
Experimental and numerical investigation of the properties of the Hot Mix Asphalt Concrete with basalt and glass fiber
}

\author{
Mahmoud Ameri, Mehdi Nemati, Hamid Shaker \\ Iran University of Science and Technology, Tehran, Iran. \\ Ameri@iust.ac.ir,mah_nemati@civileng.iust.ac.ir,b_shaker@civileng.iust.ac.ir
}

Faezeh Jafari

Department of Civil Engineering, Malayer University, Malayer, Iran. faeze_jafari666@yahoo.com

\begin{abstract}
In the recent decades, different kinds of fiber materials are used for improving the asphalt mixture performance. Meanwhile, different kinds of fiber are used excessively due to their desirable physical and chemical properties and their easier application. The main purpose of this research is to evaluate the characteristics of the asphalt mixture while using basalt fiber and glass fiber. In order to provide asphalt samples, these two types of fibers are used in different percentages. In this way, 42 samples (with different percentages of fiber and bitumen) were made using Marshal Hammer. In the next step, while constructing 63 asphalt samples using a gyratory device, then mix asphalt conventional tests include the determination of indirect tensile strength, moisture sensitivity test, and resilient modulus and creep tests performed. The results of this research indicate that using these two types of fibers increased the percentage of optimum bitumen and marshal resistance. At best, adding $0.1 \%$ glass fiber resulted in $13 \%$ increase in marshal resistance. Finally, ANFIS-GUI was used to estimate the experimental result and the feasibility of employing neural fuzzy network to predict the laboratory data have been evaluated.
\end{abstract}

KEYWORDS. Hot asphalt mixture; ANFIS; Experimental test; Basalt and glass fiber.

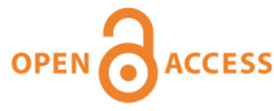

Citation: Ameri, M., Nemati, M., Shaker, H., Jafari, F., N., Experimental and numerical investigation of the properties of the Hot Mix Asphalt Concrete with basalt and glass fiber, Frattura ed Integrità Strutturale, 50 (2019) 149-162.

Received: 04.07.2019

Accepted: 29.07.2019

Published: 01.10.2019

Copyright: (C) 2019 This is an open access article under the terms of the CC-BY 4.0, which permits unrestricted use, distribution, and reproduction in any medium, provided the original author and source are credited.

\section{INTRODUCTION}

$\mathrm{S}$ ince the invention of asphalt as a composite material for the road pavement, scientists and engineers have always sought to find a material to improve its properties [1]. The application of fibers for promoting the behavioral properties of various materials is an old idea, as the fiber has been used 4000 years ago for the reinforcement of clay soil and 2000 years ago for building the Great Wall of China [1]. The basalt and glass fiber used in the mix design for asphalt concrete has been shown in various studies; for example, Ibrahim et al in 2009 used basalt in the mix design for asphalt concrete. This research explored the basalt used in the cities of Jordan as filler in the mix design of asphalt 
concrete. Replacing $20 \%$ basalt in the mix design led to an increase in all the behavioral properties of the asphalt [1]. Morova in 2013 used the basalt fiber in the hot-mix asphalt concrete. In this research, the asphalt strength from $0-2 \%$ basalt was used in the mix design. The results of this study show that the use of basalt as $0.05 \mathrm{wt} \%$ of bitumen will have the best results [2]. Zheng in 2014 studied the fatigue of asphalt reinforced with basalt fiber, the results of which show that the basalt improves the behavioral properties of the asphalt, such as tensile strength, maximum curving tensile stress, curving stiffness modulus, and fatigue properties [3].Using ESEM analysis, Gao in 2018 analyzed the basalt-reinforced hot-mix asphalted concrete. In this study, it was shown that the scanning electron microscope is capable of examining the adhesion between fibers and asphalt in different compounds. It was found that the basalt fibers with adhesion between the asphalt components contribute to the increased strength properties of the made asphalt [4]. Lachance in 2016 evaluated the effect of glass in the mix design of hot-mix asphalt concrete. The purpose of the study was to investigate the possibility of using the recycled glass particles in asphalt mixtures and study the equivalent properties and performance instead of the conventional mixture. To this end, an asphalt mixture (ESG14) was first tested with different glass contents according to the design method of the International Institute of Quebec. Then, the performance of the samples against thermal cracking and the stiffness of the asphalt mixture were investigated with different glass contents [5].

Saltan in 2015 used the glass fiber in the hot-mix asphalt concrete. The glass wastes used for $4.0 \%, 4.5 \%, 5.0 \%, 5.5 \%$, $6.0 \%$, and $6.5 \%$ bitumen in the mix design of hot-mix asphalt concrete was found to be effective in improving the asphalt strength properties [6]. Arabani (2011) studied the dynamic properties of asphalt using glass wastes. The results of the research showed that the application of glass waste can improve the dynamic properties of asphalt [7]. The stiffness model used in the present study was obtained by replacing $\% 5, \% 10, \% 15$ and $20 \%$ glass in the mix design at 5,10 and $20^{\circ} \mathrm{C}$. The results show that the temperature increase leads to a reduction in the stiffness modulus, and the replacement of $15 \%$ glass particles in the mix design, which leads to an increase in the stiffness modulus of the asphalt [8]. Ozer in 2018 used the neural network method to estimate the fatigue cracking using the accelerated testing in accordance with the mix design for the asphalt. In this research, a new numerical algorithm was used to estimate the behavioral properties of asphalt and the results showed that this method is appropriate for estimating the behavioral properties of asphalt [9].

The purpose of this study is to investigate the behavioral properties of the asphalt mixtures modified with the combination of basalt and glass fiber additives. For this purpose, it is tried to perform resilient modulus, dynamic creep, and indirect tension tests for finding the correct percentage of bitumen and obtain the optimal percentage of additive in each of the experiments. Then, the experimental results are estimated using the neural network models and the efficiency of neural network models is evaluated for the estimation of the results. The neural network used to estimate the behavioral properties of materials in laboratory research has recently been adopted by researchers. However, the conducted studies are in the field of concrete mix design and there is little research on the mix design and the prediction of behavioral properties. For example Kaur in 2000 used the fuzzy method to estimate the laboratory results. Input data to the neural network models in this research are the construction materials, pavement thickness, road age and traffic count as the input of the neural network and are intended to estimate the thickness of the asphalt. The Visual Basic environment is used to build the neural network models. After performing laboratory investigations, the neural network method is used to estimate the experimental results and to evaluate the robustness of the neural network in the estimation of the results [10]. Sodikov in 2005 emphasized the importance of prediction cost highway project with using neural network method. Lack of preliminary information, lack of database of road works costs, data amusingness, lack of an appropriate cost estimation methods are some major problem in high way project [11]. Tapkin in 2010 employed MLP to estimate physical and mechanical properties of the asphaltic mixture with PP fiber. In this study, neural network method was employed to predict laboratory test data such as Marshall Stability and flow tests [12].

In this research, due to the fact that the temperature of the asphalt wearing coarse affects its performance (stiffness and cracking on the asphalt surface), the neural network is used to estimate the temperature of the asphalt wearing coarse. The main goal of this study is to investigate the physical characteristics of the asphalt mixtures by combining basalt and glass fiber. To do this, marshal stability, resilient modulus, indirect tensile strength, and dynamic creep were done to determine the optimum percentage of these two modifiers, then laboratory test estimation was done through this method and the capability of ANFIS was evaluated.

\section{MATERIALS}

I

$\mathrm{n}$ this research, for producing asphalt samples without additive and conducting the experimental test, limestone aggregates were used for making gravel and sand of each mixture. Moreover, stone powder was used as filler (material passing the sieve 200) [13]. The mentioned material was taken from Taloo (in east of Tehran- asphalt 
factory). Fig. 1 shows the grading of the used aggregate.

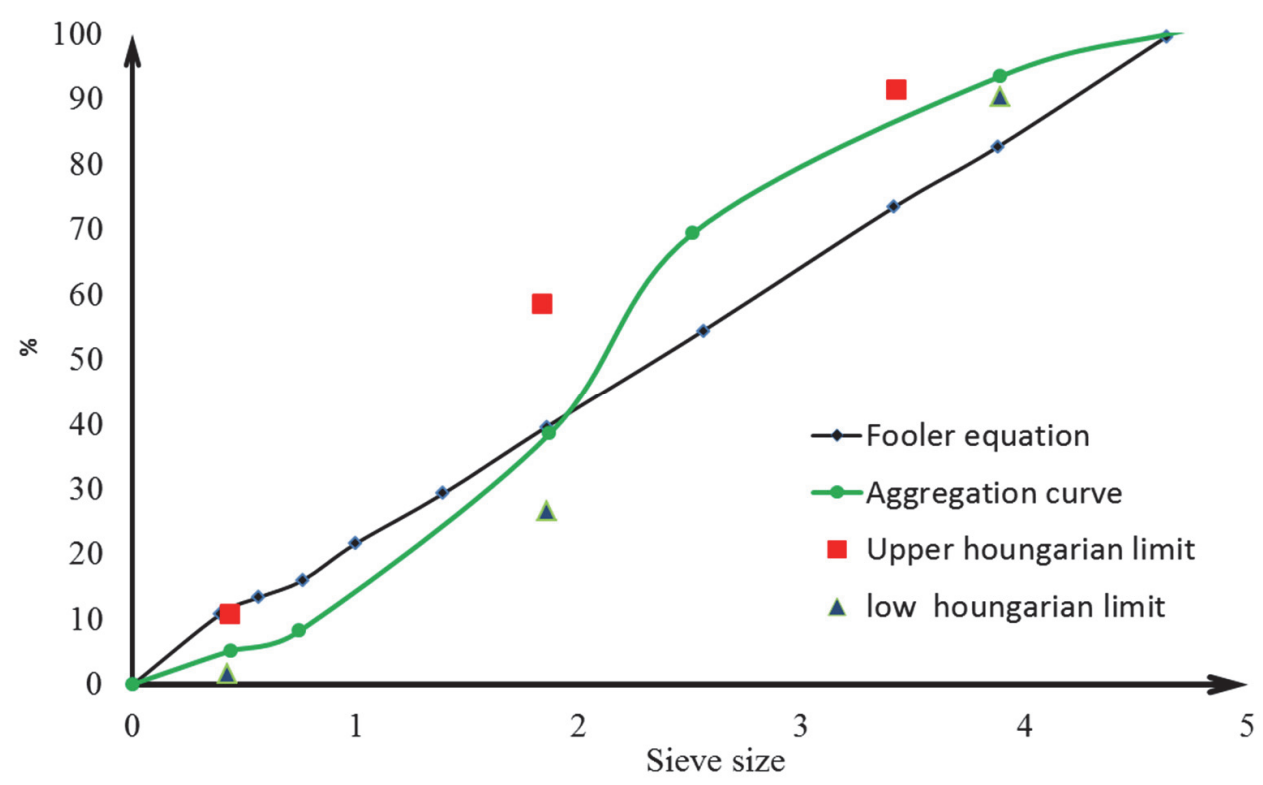

Figure 1: Particle size distribution for stone mastic asphalt mixture.

\section{The characteristics of the used fiber}

The fibers used in this research are basalt and glass which are $6 \mathrm{~mm}$ long. Their characteristics and shape of these materials are shown in Tab. 1 and Fig. 2. In this research, $\% 1,2 \%, 3 \%$ glass fiber and $\% 1,2 \%, 3 \%$ basalt fibers were used.

\begin{tabular}{cccc}
\hline \multicolumn{2}{c}{ Characteristic } & Glass fiber & Basalt fiber \\
Color & & White & Grey \\
Length & $(\mathrm{mm})$ & 6 & 6 \\
Diameter & $(\mu \mathrm{m})$ & 13 & 8 \\
Density & $\left(\mathrm{gr} / \mathrm{cm}^{3}\right)$ & $2.5-2.6$ & 2.5 \\
Melting point & $\left(\mathrm{C}^{\circ}\right)$ & 1500 & 1505 \\
Tensile strength & $(\mathrm{MPa})$ & 3000 & 3000 \\
Strain rate & $(\%)$ & 3.5 & 3 \\
\hline
\end{tabular}

Table 1: The basalt and glass fiber property [14].

\section{Mixture design and determination of optimum bitumen percentage}

Samples were produced according to the ASTMD1559 standard [15]. The bitumen and aggregates were mixed together at $145^{\circ} \mathrm{C}-150{ }^{\circ} \mathrm{C}$ and the gyratory compactor were used to compact samples. During preparation of samples, fibers (glass and basalt) with specified percentage were added to the mixture. $7 \%$ void ratio was employed to make compaction of indirect tension samples as well as the control samples were tested for other experimental result. Next, the stone material was dried in the oven for 24 hours at $170{ }^{\circ} \mathrm{C}$. Therefore, the moisture of the stone material is evaporated during this process. In order to reach the maximum Marshal stability, minimum flow, optimum void ratio and absorbed bitumen percentage, the optimum bitumen percentage should be compared to the proper bitumen percentage. Ultimately, the optimum bitumen percentage should satisfy all the above mentioned criteria. To do this, 18 control samples for asphalt mixture was used and once the corresponding tests were done, the optimum bitumen percentage was determined. The selected percentage of the bitumen for the control samples were 4, 4.5, 5, 5.5, 6, 6.5 percent of the material weight and for each percent of the bitumen three samples were made. Moreover, 24 other samples were made for basalt and glass fiber mixture to predict the percentage of optimum bitumen. It should be mentioned that the selected percentage for basalt and 
glass fiber (for determining the optimum bitumen percentage) were $0.3 \%$ of the weight of the asphalt mixture. Tab.3 shows control parameters of optimum bitumen percentage for 3 group samples.

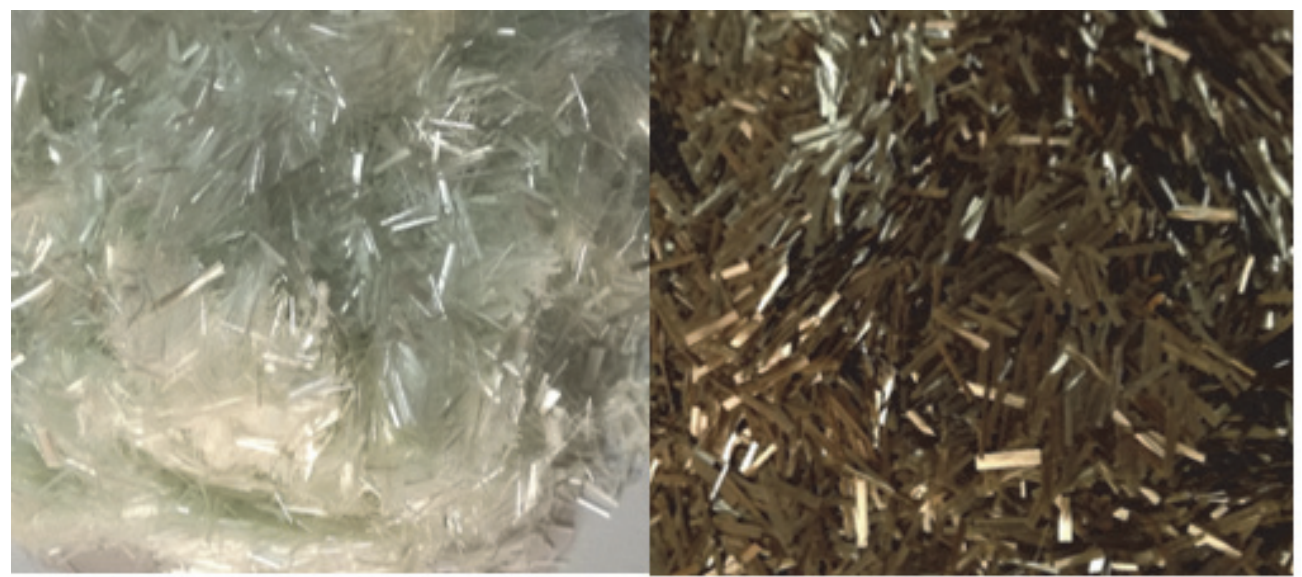

Figure 2: The shape of fiber (a) basalt fiber b) glass fiber [14].

\begin{tabular}{cccccc}
\hline & & \multicolumn{2}{c}{ Glass fiber } & \multicolumn{2}{c}{ Basalt fiber } \\
Element & Oxide & Oxide mass & Element mass & Oxide mass & Element mass \\
percentage & percentage & percentage & percentage \\
$\mathrm{Al}$ & $\mathrm{Al}_{2} \mathrm{O}_{3}$ & 11.86 & 6.3 & 17.35 & 9.17 \\
$\mathrm{Si}$ & $\mathrm{SiO}_{2}$ & 58.25 & 24.24 & 42.43 & 19.76 \\
$\mathrm{Ca}$ & $\mathrm{CaO}$ & 21.09 & 15.05 & 8.88 & 6.37 \\
$\mathrm{Fe}$ & $\mathrm{Fe}_{2} \mathrm{O}_{3}$ & 0.3 & 0.21 & 11.68 & 8.17 \\
$\mathrm{~K}$ & $\mathrm{~K}_{2} \mathrm{O}$ & 0.43 & 0.36 & 2.33 & 1.94 \\
$\mathrm{Mg}$ & $\mathrm{MgO}_{\mathrm{Na}}$ & 0.54 & 0.32 & 9.45 & 5.7 \\
$\mathrm{Ni}$ & $\mathrm{Na}_{2} \mathrm{O}$ & 0.3 & 0.22 & 3.67 & 2.81 \\
& $\mathrm{TiO}_{2}$ & 0.41 & 0.25 & 2.55 & 1.53 \\
\hline
\end{tabular}

Table 2: Component for basalt and glass fiber material [14].

\begin{tabular}{cccc}
\hline Parameters & Glass & Basalt & $\begin{array}{c}\text { Control } \\
\text { Samples }\end{array}$ \\
Marshal stability at optimum percentage & 883 & 807 & 854 \\
Flow at optimum percentage & 4.2 & 3.6 & 3.15 \\
Percentage of empty space filled with bitumen & 74.7 & 75 & 74.3 \\
Percentage of empty stone materials per percentage of possible bitumen & 15.6 & 15.7 & 15.2 \\
\hline
\end{tabular}

Table 3: Parameters for controlling optimum bitumen percentage.

\section{EXPERIMENTAL TEST}

\section{Indirect tensile strength test}

$\mathrm{I}$ ndirect tensile strength test is often used for evaluation of moisture sensitivity of asphalt mixtures. The produced asphalt samples are divided into two groups, dry and wet. In order to produce dry samples, before breaking them, their temperature should reach to the room temperature. For this purpose, the samples can be put in plastic bags to prevent it from getting wet and then they should be saturated at least for 1 hour in water at $25^{\circ} \mathrm{C}$ temperature. For producing wet sample in vacuum, the wet samples should be put in vacuum instrument. Saturate ratio should be between $55-80$ percent of the asphalt vacant place. If the samples saturation is more than $80 \%$, that sample should be removed. Then, the samples are put vertically between the two jaws of the indirect tensile strength instrument. Diagonal load is 
applied to the sample by $50 \mathrm{~m} / \mathrm{min}$ speed so that the load reaches to its maximum amount and the sample breaks. After recording the maximum load, the indirect tensile strength of the asphalt samples is determined. The higher indirect tensile strength shows that the mixture had a proper resistance against the moisture damage. Also, the sample which can bear high strain before breaking, have higher cracking resistance, compared to the samples with low strain [16].

$$
I T S=\frac{2 * P_{\max }}{\pi^{*} t^{*} d}
$$

where:

ITS $=$ indirect tensile strength $(\mathrm{Pa}), P_{\max }=$ maximum applied load $(\mathrm{N}), \mathrm{t}=$ thickness of $\operatorname{specimen}(\mathrm{mm}), \mathrm{d}=\operatorname{diameter}$ of specimen $(\mathrm{mm})$.

\section{Resilient Modulus}

The Resilient Modulus is used for evaluation and analysis of comparative quality of the asphalt mixtures as the input data of pavement design. In this study, the UTM5 device at $25^{\circ} \mathrm{C}$ and the semisynthetic load was employed such that the selected load is $400 \mathrm{~N}$. Finally, the mean of the five last resilient modulus steps was collected and named the resilient modulus of the mixtures. Fig. 3 shows UTM5 set-up which was used for resilient modulus and dynamic creep test.

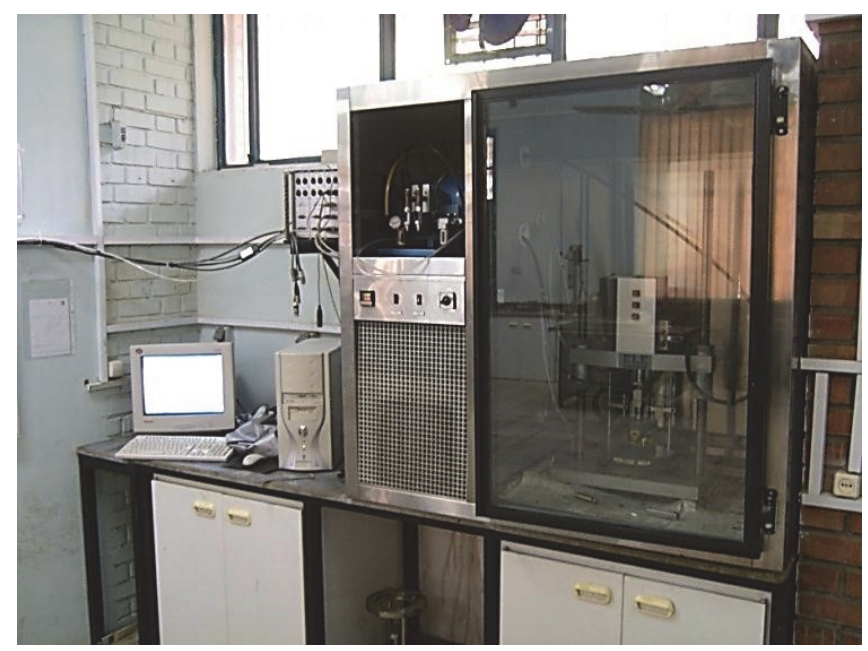

Figure 3: UTM5 set-up which was used in the experimental test.

\section{Dynamic creep}

Dynamic creep test which shows the permanent deformation of asphalt mixture is recognized as one of the most prevalent damages in the hot mix asphalt concrete research. Several thousand loads which were repeated in cyclic pattern have been employed to make permanent displacements. To reach this aim, UTM5 was used to perform dynamic creep test, the stress level of $450 \mathrm{kPa}$ and a temperature of $50^{\circ} \mathrm{C}$ is considered as a constant variable in this research and sample loading is started up to 0.01 strain rate [17]. The diameters of the cylinders were 100 to 150 (mm) and the height of them is $60(\mathrm{~mm})$ [18]. According to the Witzak theory [18], the number of beginning loading process before the starting of the third region is considered as a flow number. The numbers of cycles are equal to the minimum value of the strain rate which was derived from the strain rate graph.

\section{Neural network part}

An adaptive neuro-fuzzy inference system (ANFIS) is a type of neural network which was worked according to TakagiSugeno fuzzy inference system. This method used from the futures of both neural networks and fuzzy logic system. In this study, this method is employed due to estimate asphalt mixture's properties. For reach this goal, all laboratories data which were extracted through experimental test with their variables were imported to MATLAB GUI software as the output variable. The previous studies that used this method considered the output and input variable in MATLAB as a fixed variables [19], but, in this present study, the input variables were produced randomly with using the average and variance value which obtained from experimental test. To do this, the input variables are additive percentage to bitumen 
combination (glass fiber and basalt) as well as the output variables are the value of flow number, resilient modulus and tensile strength in wet and dry condition, marshal stability test. The variance for input and output values have been considered $0.1 *$ mean value with log-normal fit distribution. After generating data with MATLAB software and experimental test, ANFIS- GUI and experimental data (output and input values) were used in order to prediction process. Ultimately, the number of data extracted from ANFIS GUI is 99 for marshal stability test and 99 for flow as well as 63 for other test such as resilient modules, ITS and flow number. All variables are divided into three subsets data as train, test and validation group. The possible surfaces for output variables were predicted according ANFIS rules such that these surfaces show to what extend different additives able to change output variables.

\section{RESULT}

Selection of optimum bitumen percentage for three sample groups

A fter calculating the optimum bitumen percentage for the fiber-reinforced asphalt mixtures, the samples were prepared with $0.1,0.2,0.3,0.5$ and $0.7 \%$ basalt fiber and glass. The results of the Marshall stability are presented in Fig. 4. In all figures BF was used as indicator for basalt fiber and GF was used for glass fibers.

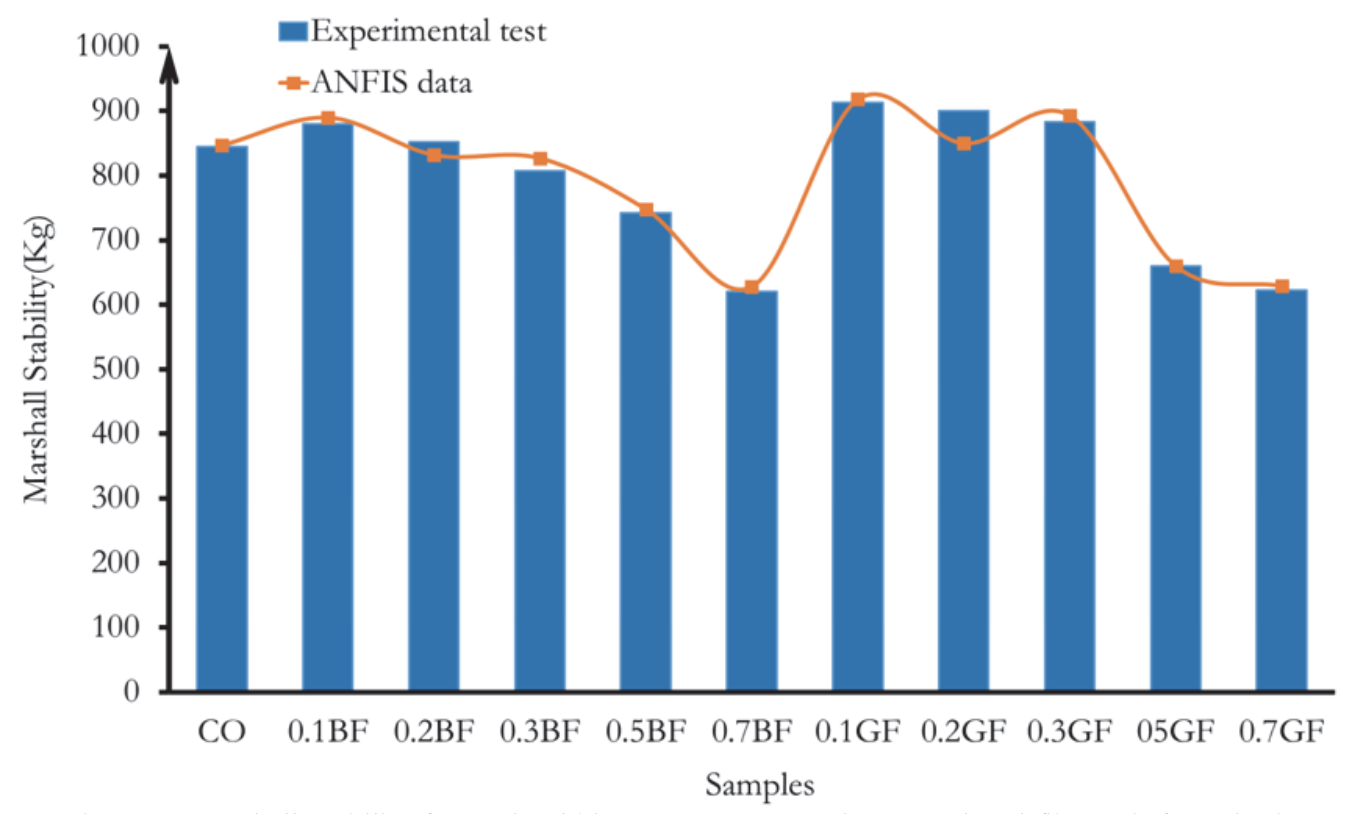

Figure 4: Marshall Stability for optimal bitumen percentage in control and fiber-reinforced mixtures

The results of Fig. 4 show that the Marshall stability could be increased if the fiber is used in the asphalt mixtures. In fact, the use of $0.1 \%$ basalt fiber resulted in $4 \%$ increase in the Marshall stability comparing the control sample, but it hereafter led to the loss of Marshall Stability, so that in the case of using $0.3 \%$ fiber, the Marshall stability reached about $800 \mathrm{~kg}$. This can be explained by the fact that the use of fibers up to $0.2 \%$ probably caused the reinforcement of the asphalt mixtures, but hereafter, the fiber balling phenomenon was occurred. Therefore, increasing the percentage of fiber intensifies the reduction of the Marshall stability.

The same is true for the variations in the Marshall stability for the glass-fiber-reinforced samples, but there are also some differences. For example, if the maximum value of the glass fiber is used, the Marshall stability for the modified sample will not be less than the control sample. It should be noted that when using $0.1 \%$ glass fiber, a $13 \%$ increase will be observed in the Marshall stability. On the other hand, as can be seen, increasing the Marshall stability for the samples made with glass fiber is far more than those containing basalt fibers. There are two main reasons to justify this difference: first, the difference between the Marshall Stability values may be due to the difference in the bitumen percentage of the samples. Second, the effect of the chemical properties of both types of fibers should not be considered the same and it is possible that the difference in the values of the Marshall stability is due to the properties of the constituent materials of the fiber. 
In general, it could be stated that there is no significant change in the use of glass fibers, but if the glass fiber is used, the relative improvement will be achieved; although; if more glass fiber is used, the Marshall stability will be decreased. At best, adding $0.1 \%$ glass fiber resulted in a $13 \%$ increase in the Marshall stability. Previous studies showed that adding glass fiber to the asphalt mixture causes $45 \%$ increase in the Marshall stability. On the other hand, according to research, the addition of fiber to the asphalt mixture decreases the parameter by $10 \%$. It could be concluded that more precise research is needed on the use of glass fiber in the asphalt mixtures. Moreover, figure 7-10 show the result of experimental test which were obtained from laboratory test and ANFIS method .The results of ANFIS are close to experimental test and that means this way can predict experimental result correctly. ANFIS has been employed as neural network in some other previous researchers [19] and in these studies, also this relationship (proximity between laboratory and numerical data shows the efficiency of ANFIS method.

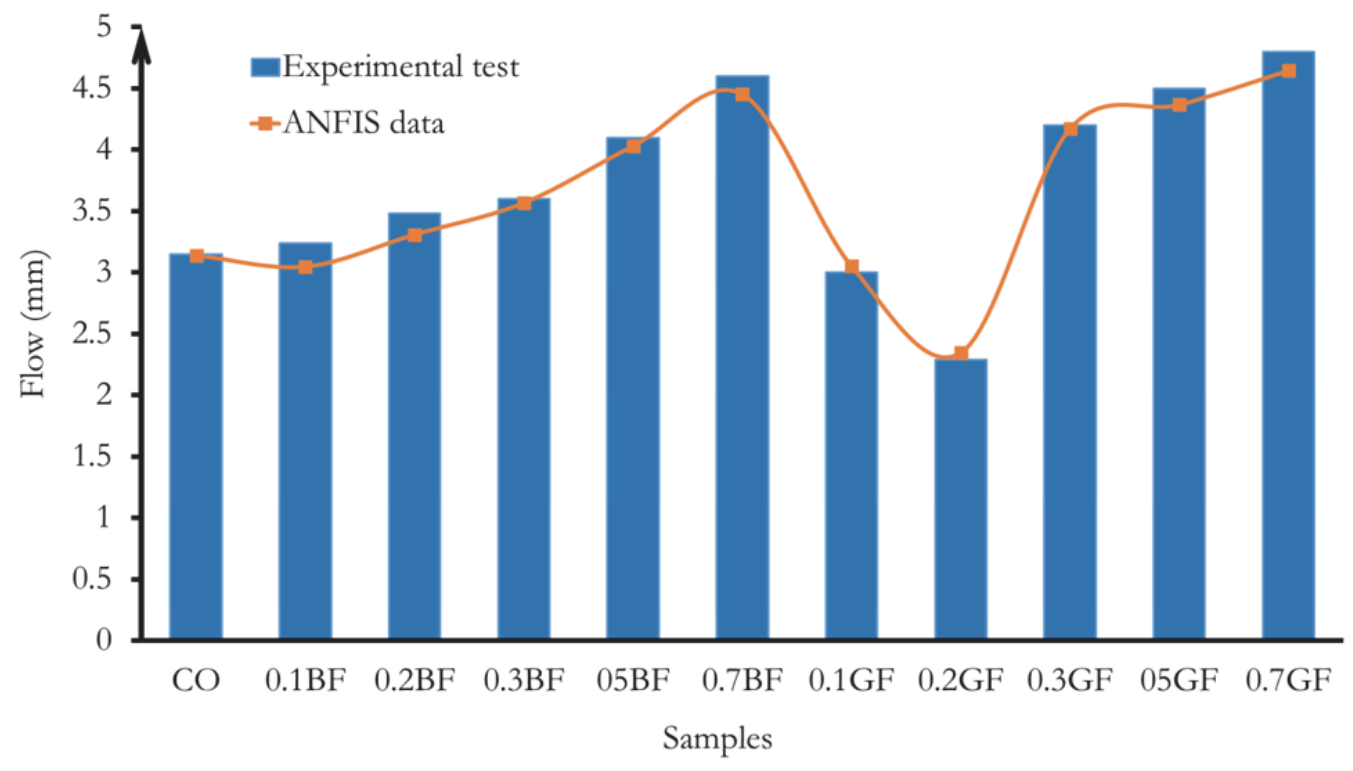

Figure 5: Flow value for different samples

\section{Flow value}

Fig. 5 presents the values for the flow in the control and modified samples. As can be seen, there will generally be an increase in the flow value when using the fibers. The use of $0.3 \%$ basalt fibers led to a $10 \%$ increase in the flow value. The glass fibers also increased the flow value, so that the flow value for the samples made with $0.3 \%$ glass fiber reached 4.2 $\mathrm{mm}$. On the other hand, it is observed that for the percentages higher than $0.3 \%$ fiber, the flow value exceeded the allowable limits of the regulation and the flow value was significantly increased, so that for the samples made with $0.7 \%$ fibers (whether basalt or glass), an increase about 50\% is achieved. As mentioned earlier, based on the results of the Marshall Stability and flow, 0.5 and $0.7 \%$ fibers were removed and the remaining tests were performed using other percentages. In order to justify the flow increase in the case of using basalt and glass, two approaches are considered: it seems that even though the basalt and glass fibers have a high melting temperature, the surface of the fiber melts during the asphalt curing and increases the viscosity of bitumen. This causes the bitumen to be less adsorbed onto the surface of the aggregates and to remain in the space between the aggregates. In this way, the presence of additional bitumen in aggregates increased the flow of samples. On the other hand, the flow, in fact, is the rate of sample deformation at the moment of failure. Now, the fibers cause the bonding and adhesion of different parts of the sample to each other and make the specimen exhibit more deformation at the moment of failure.

Previous studies have discussed the glass fibers and their application to hot-mix asphalt concrete. The flow number is increased in previous studies for increasing the percentage of glass fiber. For example, Taherkhani (2016) added glass fiber and Nano clay in the mix design of the hot-mix asphalt concrete, adding 0.2, 0.4 and 0.6 glass fiber. In this research, it was tried by providing more percentages (0.1-0.7) and comparing the results to show that the flow number is increased with the use of glass fiber in the mix design. The increase for 0.6 glass fibers is 1.16 times the control sample in the Taherkhani study [20], and in this study, it is approximately 1.4 times. It could be stated that the addition of glass fibers led to the maximization of the flow number. On the other hand, the results of previous research, such as Nihat Morova [21] on the use of basalt in the mix design for asphalt concrete. This research indicates an increase in the flow number for adding 
basalt to the asphalt mix design. The results of this study also show that the use of glass fibers can further increase the flow number. The placement of the both materials together in the same mix design shows that the application of glass fiber comparing the basalt for 0.3 optimum bitumen, can lead to the maximum increase in the flow number, while in the percentages below 0.3 ; the use of basalt fiber further changes the flow number.

\section{Test results of indirect tensile strength}

A total of 42 samples were taken to perform the indirect tensile strength test. According to experimental ITS test which was mentioned in previous part of this paper, half of the specimens were dried and the rest were tested in the saturated state. It should be noted that in order to minimize the errors in each percentage of the fibers, three samples were made, and the results are presented based on the averaging. Fig. 6 shows the results of the indirect tensile strength test for the dry specimens.

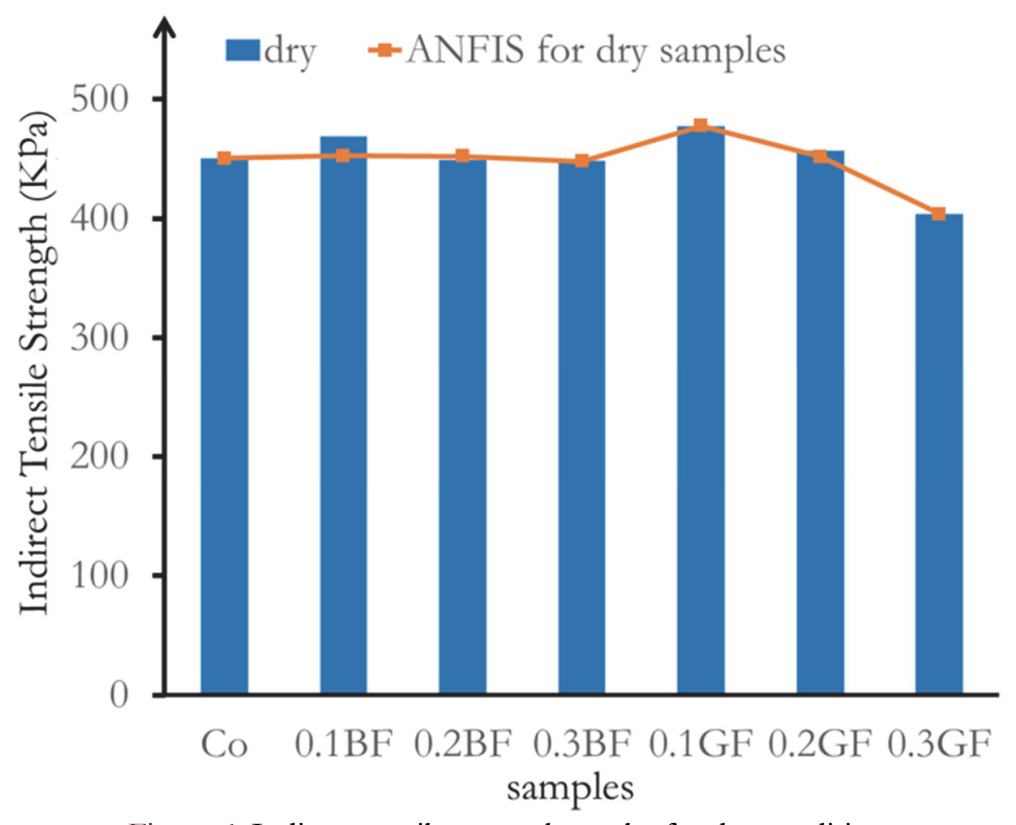

Figure 6: Indirect tensile strength results for dry condition.

Generally, the tensile strength is increased by adding fibers to the asphalt materials. The highest increase is seen in the case of using $0.1 \%$ glass fiber, which is about $6 \%$ higher than the control sample. The same effect is observed if the same amount of basalt fiber is used. On the other hand, with an excessive increase in the percentage of fibers, there is a decrease in indirect tensile strength. The highest reduction is seen for the sample made with $0.3 \%$ glass fiber. Also, if the basalt fiber is used, the indirect tensile strength values for the different percentages of the fibers are approximately the same, but on the contrary, in the case of glass fibers, considerable variations will occur in the indirect tensile strength. Fig. (7) presents the results of the indirect tensile strength test in the saturated state.

The results of this diagram show that by increasing the percentage of basalt fiber and glass, the value of indirect tensile strength is decreased. The fibers are not resistant to moisture sensitivity, as the highest tensile strength occurs in the saturated state for the control samples and the lowest one occurs for the samples containing $0.3 \%$ basalt fiber. The results show that in the worst case, the indirect tensile strength is decreased by $26 \%$ comparing the control sample. Finally, the calculations are done for the values of the wet to dry ratio of indirect tensile strength. Information about this ratio, commonly known as TSR, is shown in Fig. (8).

Fig. 8 shows that the highest TSR belong to the control sample (89\%) and the lowest one is for the sample containing $0.3 \%$ basalt fiber (with the rate of $70 \%$ ). It should be noted that the samples with GF materials essentially do not have a high sensitivity to the moisture damages. The minimum TSR value is nearly $75 \%$ in the asphalt specimens with the samples made with $0.3 \%$ basalt fiber and $0.3 \%$ glass fiber. Regarding the negative effect of the glass fiber and basalt fiber in high percentages $(0.3 \%)$ on the performance of moisture sensitivity, it could be stated that when using the fiber, as the absorption rate of bitumen is increased, the potential for the absorption of moisture is also increased, leading to a decrease in the indirect tensile strength in the saturated state. 


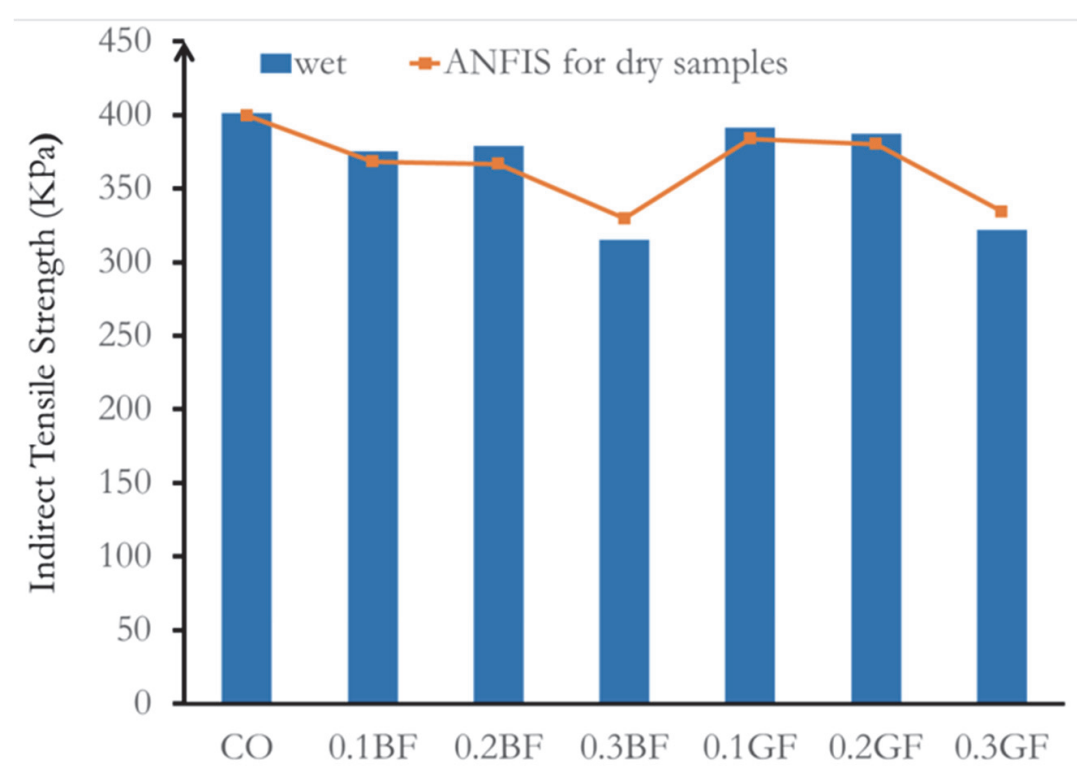

samples

Figure 7: Indirect tensile strength results for wet condition.

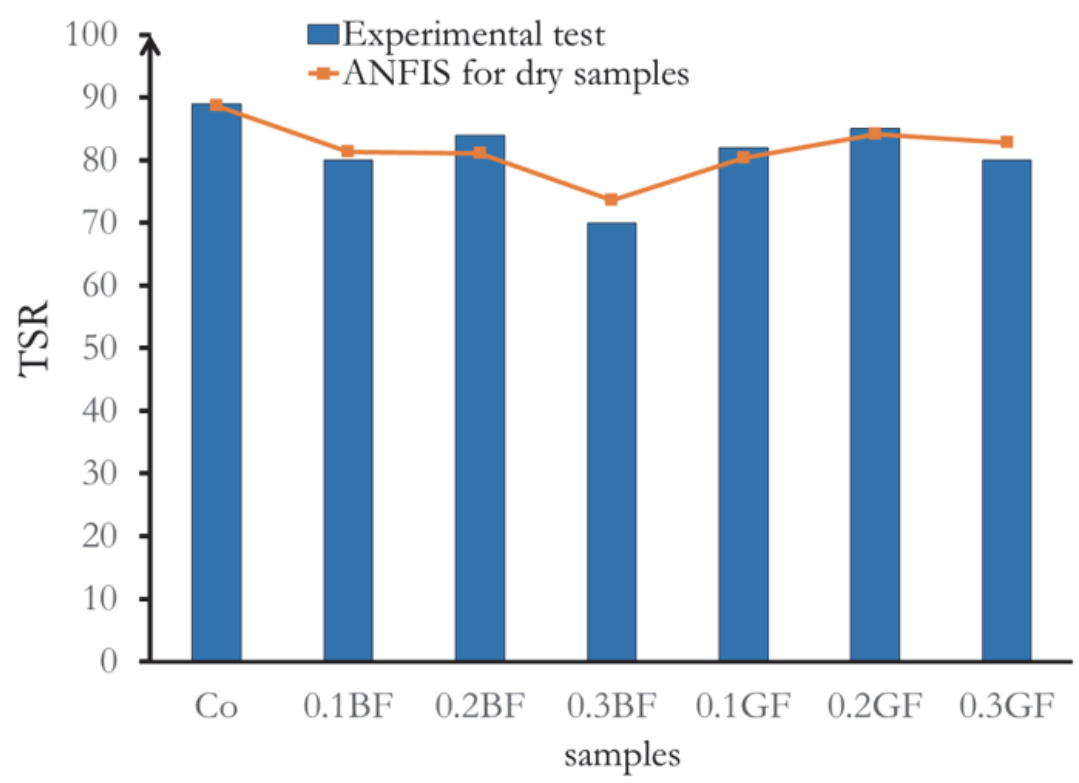

Figure 8: Tensile strength ratio (TSR) of control and fiber-reinforced samples.

\section{Resilient Modulus}

Totally, 21 specimens were built to perform the resilient modulus test, so that 3 specimens were built for each percentage of the fibers, and the amount of resilient modulus was determined by averaging for the samples containing the same percentages of fibers. Fig. (9) shows the results of the resilient modulus test for the control samples as well as the samples containing the basalt and glass fibers.

As seen in Fig. 9, increasing the amount of basalt fibers increases the resilient modulus. The highest increase in the resilient modulus is observed using $0.3 \%$ fiber, so that the resilient modulus is increased by about $50 \%$ (from 2660 to 3963 $\mathrm{MPa}$ ). The use of glass fibers also led to an increase in the resilient modulus, so that the resilient modulus of the samples containing $0.2 \%$ glass fiber reached over $3300 \mathrm{MPa}$.

In this part of the research, we first compare the results of the present research with previous studies to determine how consistent the results with the previous research. It should be noted that the research on the basalt and glass fiber 
additives for testing the resilient modulus has been considered in few studies. The present study tries to compare the both additives while working on them.

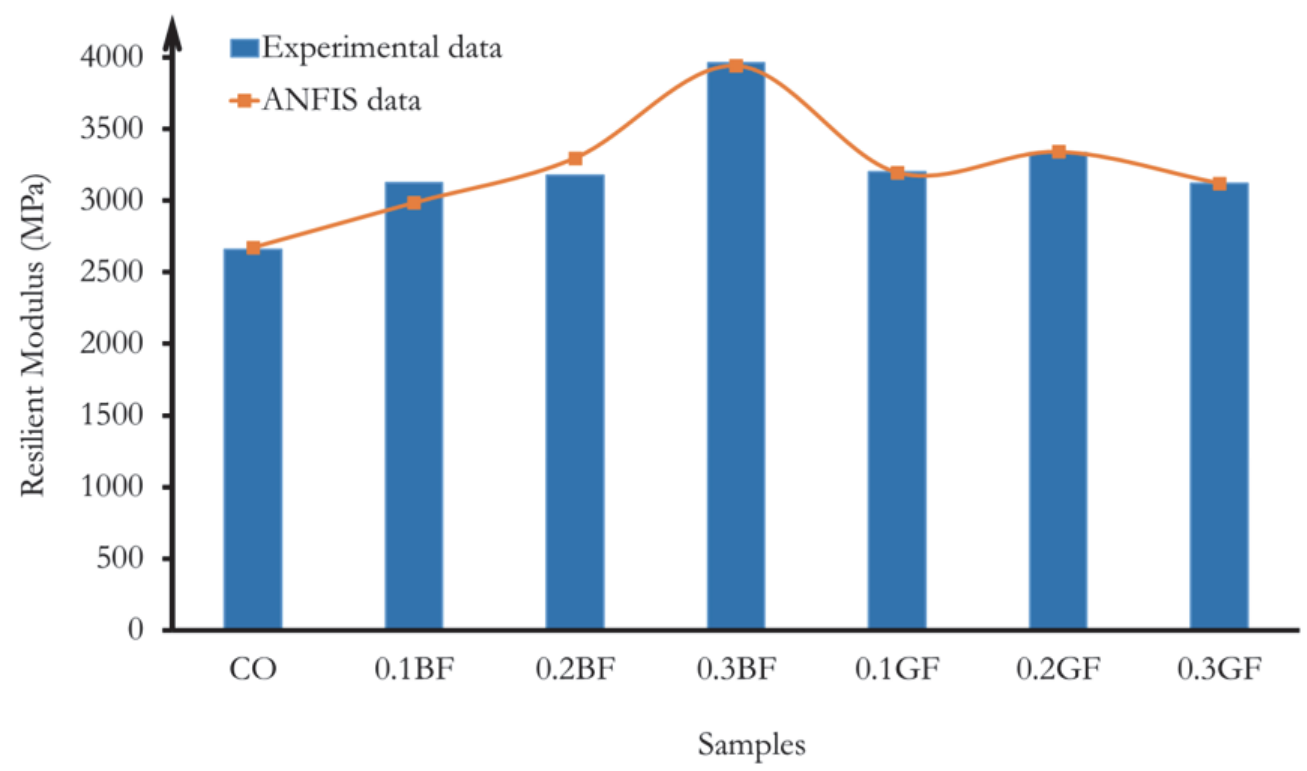

Figure 9: Test results of resilient modulus.

In the Marshall test, the amount of strength is increased with increasing the fiber percentages, but in this experiment, it is observed that with the increase in the fiber percentage, the amount of the resilient modulus is raised. Therefore, at first glance, it seems that the results of this test are not consistent with other previous tests. However, carefully looking the test procedure, one can answer the question of why the results of the experiments are in conflict. As it is known, in the Marshall test, the compressive loads are applied and the specimen is subjected to the compression till the failure. Basically, the use of reinforcing materials in the process will not be so useful with applying the compressive load and may have a negative effect on the compressive strength. However, the resilient modulus test has a tensile nature and, generally, if the fibers are used, the tensile properties of the asphalt mixture are increased.

\section{Flow number}

It is observed that the addition of fibers increases the flow number, so that the flow number for the control sample is about 1500 , and when using $0.1 \%$ basalt fiber, it is increased by about $20 \%$ to 1800 . An increase in the percentage of basalt fiber leads to a decrease in the flow number. This decrease is such that using $0.3 \%$ basalt fiber causes a $21 \%$ decrease in this parameter. The glass fiber has the same functionality as the basalt fiber, so that the flow number is gradually reduced by increasing the glass percentage. However, it should be noted that the effect of glass fiber in the higher percentages is greater than that of the basalt fiber. In the creep test, increasing the flow number means that the asphalt mixture is relatively harder and the rutting potential in such samples is relatively lower. It is inferred from Fig. (10) that the samples containing $0.1 \%$ fiber have the best performance against the rutting.

Nihat Morova in 2013 studied the use of basalt as different percentages of bitumen. In this research, 4.5, 5 and 5.5\% bitumen were used in the mix design with different percentages of basalt fiber $(0-2 \%)$. The maximum flow number in this research was 1\%, and for all three percentages of bitumen in the Morova's research is $1.5 \%$ and hereafter, it is $1 \%$. In that study, the highest flow number was for 5 and $5.5 \%$ bitumen (highest flow number). In this study, the optimal bitumen percentage was obtained for $5.1 \%$ basalt samples, and the results of Morova's research showed that for the optimum bitumen percentages of 5 and $5.5 \%$, the maximum flow number is obtained for replacing $1-1.5 \%$ basalt. Also, according to Morova's research and the current results, the excessive use of 2 and $3 \%$ basalt for $5 \%$ bitumen leads to a decrease in the flow number [21].

Subsequently, testing on the addition of glass fiber in the mix design of hot-mix asphalt concrete showed that the use of $1 \%$ glass fiber also resulted in the improvement of the flow number, which compared with the basalt samples, the glass fiber-reinforced samples had higher values. Nguyen (2013) used the glass particles in the hot-mix asphalt concrete [22]. The use of glass fiber in the mix design resulted in a drop in the flow number, because the researcher selected the percentage of fiber from 0 to $2 \%$, which in the present study, increasing the glass fiber to 2 and $3 \%$ resulted in a decrease 
in the flow number. On the other hand, the higher the percentage of increase in the glass fiber for both studies, the more the drop in the flow number. The results of previous research show that the flow number has not yet been compared in a specific mix design for adding basalt and glass fibers. Comparison of the results showed that the application of $1 \%$ basalt and $1 \%$ glass fiber could obtain the maximum value of flow number.

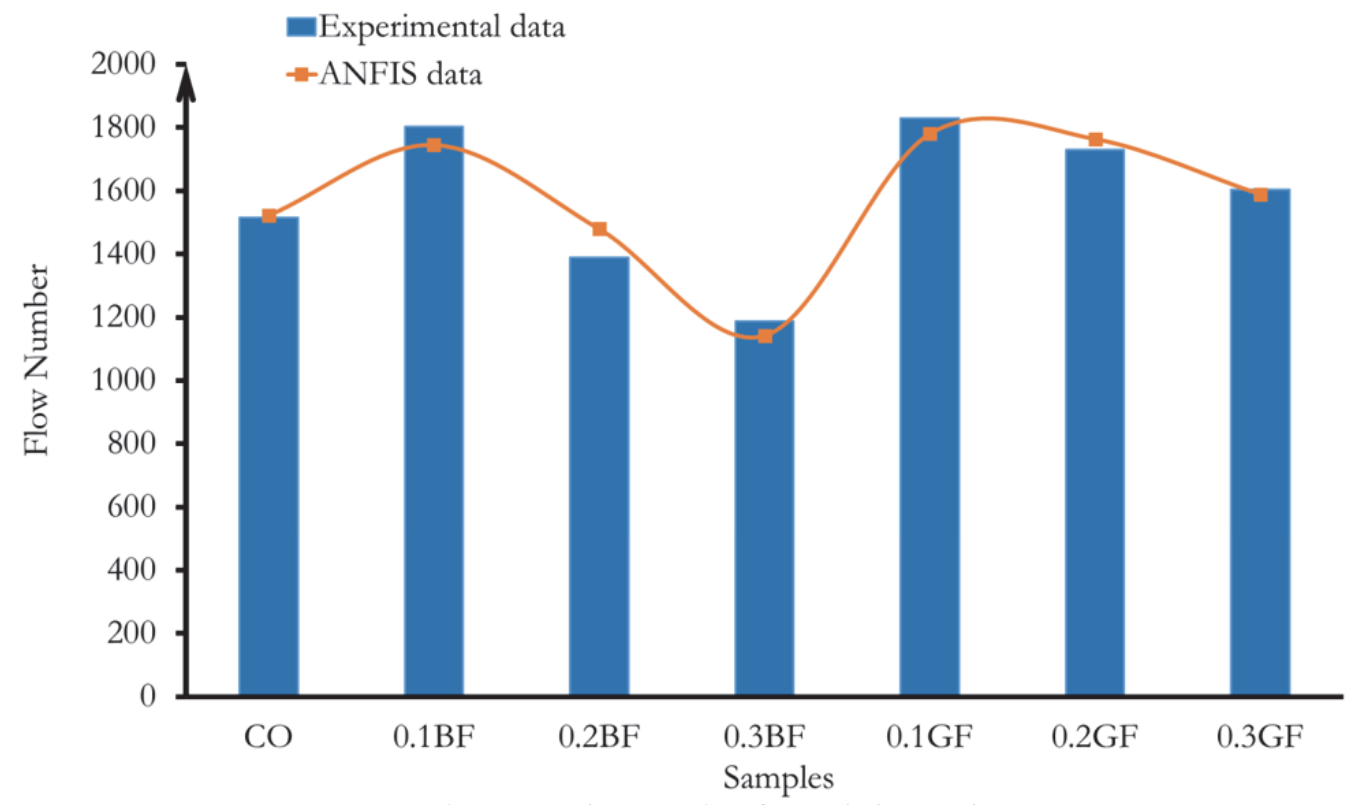

Figure 10: Flow number for asphalt samples

The decrease of the flow number in the values of 0.2 and 0.3 is due to the fact that some percentage of bitumen is kept around the fiber. This can reduce the bitumen thickness around the aggregates and reduce the strength. Although, the reduction in the strength and stiffness can increase the flexibility and improve the fatigue properties, but in order to avoid excessive reduction of bitumen thickness around the aggregates, the amount of fiber should be limited according to previous and current research. The reduced thickness of bitumen, in addition to the adverse effects on the strength, also has undesirable effects on the endurance of the mixture against moisture. In this section, it is tried to compare the results of research with other laboratory studies.

\section{NUMERICAL PART}

he proficiency and reliability of ANFIS system was checked according two parameters (R ${ }^{2}$ and MSE) based on the previous research [23]. According to this research, all neural networks such as ANFIS, ANN and SVM ways have the highest performance when the amount of $\mathrm{R}^{2}$ is near to 1 and the RMSE value is close to zero. Table 4 shows these values for ANFIS neural network which were built in this research.

\begin{tabular}{|c|c|c|c|c|c|c|}
\hline \multirow{2}{*}{ Output Layer } & \multicolumn{2}{|c|}{ Training set } & \multicolumn{2}{|c|}{ Testing set } & \multicolumn{2}{|c|}{ Validation set } \\
\hline & $R^{2}$ & RMSE & $R^{2}$ & RMSE & $R^{2}$ & RMSE \\
\hline Flow (mm) & 0.880 & 0.08 & 0.80 & 0.03967 & 0.9892 & 0.3568 \\
\hline Indirect tensile strength test $(\mathrm{kPa})$ & 0.8540 & 0.0062 & 0.94 & 0.0005 & 0.81 & 0.0025 \\
\hline Flow number & 0.9490 & 0.03967 & 0.9545 & 0.0469 & 0.8960 & 0.0560 \\
\hline Resilient modulus (MPa) & 0.9688 & 0.0420 & 0.9586 & 0.0560 & 0.8754 & 0.0610 \\
\hline
\end{tabular}

Table 4: ANFIS results for $\mathrm{R}^{2}$ values and RMSE of: training set, testing set, and validation set 
a)

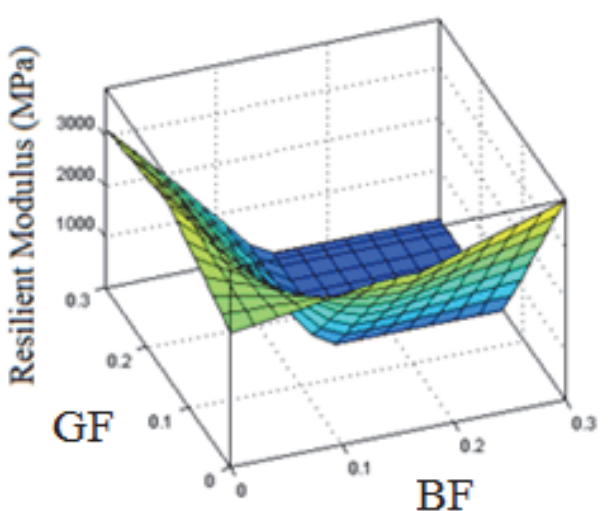

c)

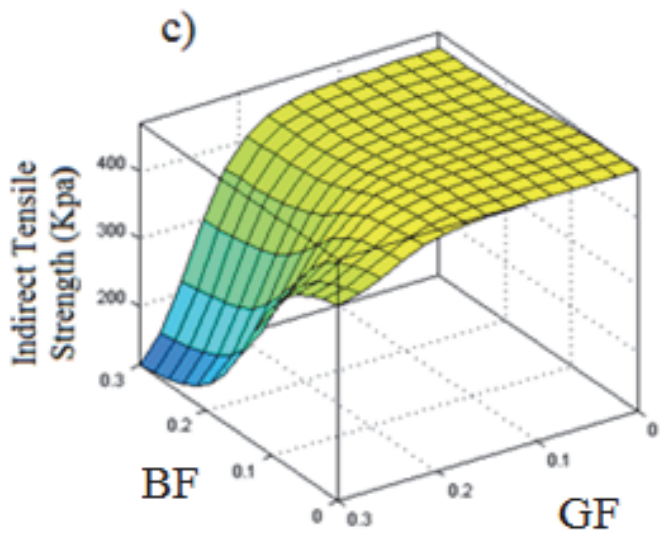

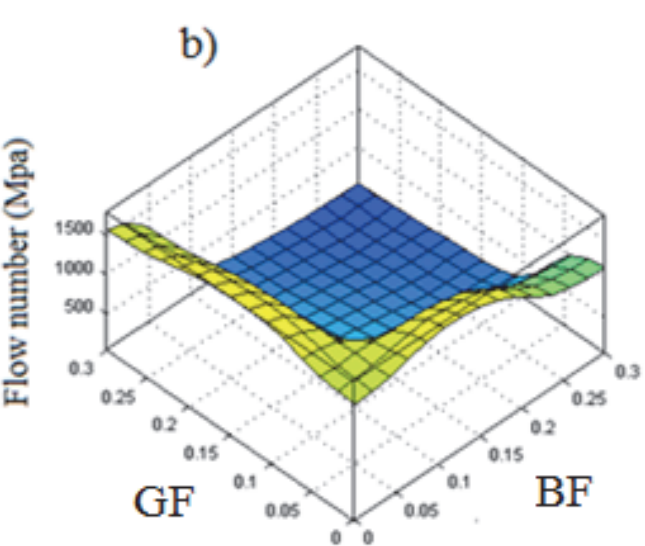

d)

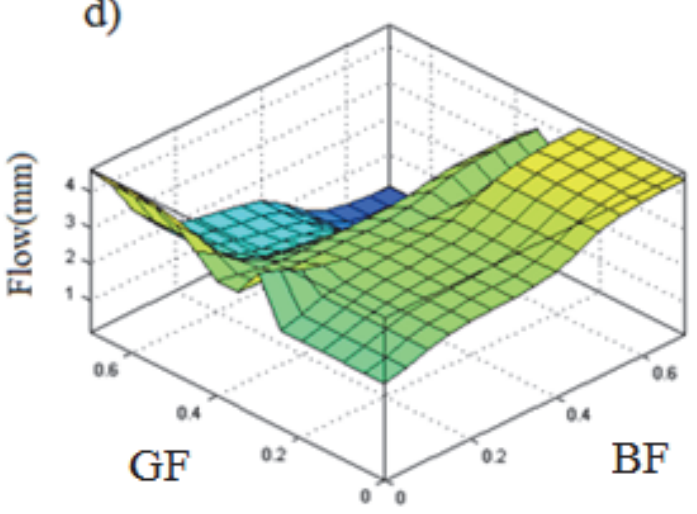

Figure 11: ANFIS result for indirect tensile test, resilient modulus and dynamic creep.

ANFIS models able to predict experimental results exactly so that the value of $\mathrm{R}^{2}$ is near to 1.00 and RMSE is near to zero. Moreover, ANFIS models, which have been produced in this research, have capability of predicting output value close to real data; Fig. 4 to 10 shows this fact. Fig. 11 shows the relationship between two input variables (fiber glass and basalt) and the output layers (flow number, tensile strength and dynamic creep and flow value). Fig.11a indicates the resilient modulus variation related to the basalt and glass fiber. This figure shows that the maximum variation of this parameter is related to $0.3 \mathrm{~B}$ (basalt) and $0.2 \mathrm{~F}$ (glass) and the surface variation decreases by reducing the value of basalt and fiber glass. Fig.11b shows the flow number surface for the basalt and fiber glass. Also, figure 11b shows the highest surface belongs to $0.2 \mathrm{~B}$ (basalt) and 0.2 glass fiber and the variation of surface decrease while the value of basalt or fiber glass have maximum value. Fig.11c shows the variation of ITS surface for the basalt and glass fiber. This figure emphasize this issue that the maximum point is for 0.2 basalt fiber and 0.2 glass fiber and this surface decrease with increasing the value of glass fiber to $0.3 \%$ and basalt fiber to $0.3 \%$. Fig. $11 \mathrm{~d}$ shows the variation of flow surface for the basalt and fiber glass and in this figure flow is known as dependent variable. This figure displays the maximum value belongs to 0.6 basalt and 0.4 glass fiber and the surface reduce when the value of basalt and fiber glass increases.

\section{CONCLUSION}

$\mathrm{I}$

$\mathrm{n}$ the present study, two basalt and glass fiber additives were used as an alternative for the optimum bitumen in the preparation of hot-mix asphalt concrete samples. After conducting the experiments test, the neural network was used for the estimation of the laboratory results. The research results show that:

- The optimum bitumen percentage for the asphalt mixture is $4.9 \%$ and for the asphalt mixture made with basalt and glass fibers is found to be $5.1 \%$ and $5.8 \%$, respectively. Generally, when using the fiber in the asphalt mixtures, the increase in the Marshall stability can be seen. At best, adding $0.1 \%$ glass fiber resulted in a $13 \%$ increase in the Marshall stability. 
- In the case of using fibers, there will be an increase in the flow value. The use of $0.3 \%$ basalt fibers resulted in a $10 \%$ increase in the flow value. The use of glass fibers also increases the flow value, so that the flow value for the samples made with $0.3 \%$ glass fiber reaches $4.2 \mathrm{~mm}$.

- The Marshall stability and flow for the samples made with 0.5 and $0.7 \%$ fibers are completely inappropriate and, accordingly, the use of these percentages is not justifiable for other tests. The results are such that when using $0.7 \%$ of fibers, the flow parameter was increased by more than $50 \%$ and exceeded the allowable limit of the regulation.

- Generally, the tensile strength in the dry state is increased by adding fibers to the asphalt materials. The highest increase is seen if $0.1 \%$ glass fiber is used. This change is such that it rises by about 5\% from 450 to $470 \mathrm{kPa}$.

- With the increase in the percentage of basalt and glass fibers, the indirect tensile strength is decreased in the wet state. The highest reduction is observed if $0.3 \%$ fiber is used, with the indirect tensile strength decreasing by more than $20 \%$ compared with the control sample.

- The highest TSR value is related to the control sample $(89 \%)$ and the lowest one is for the sample containing $0.3 \%$ basalt fiber $(70 \%)$.

- By increasing the amount of basalt fiber, the resilient modulus is increased. The highest increase in the resilient modulus is observed using $0.3 \%$ fiber, so that the resilient modulus is increased by about 50\% (from 2660 to 3963 $\mathrm{MPa})$.

- The use of glass fibers led to an increase in the resilient modulus, so that the resilient modulus of the samples containing $0.2 \%$ glass fiber is increased by $25 \%$ to over $3300 \mathrm{MPa}$.

- The addition of fibers increases the flow number, so that the flow number for the control sample is about 1500 , and when using $0.1 \%$ basalt fiber, it is increased by about $20 \%$ to 1800 .

\section{REFERENCES}

[1] Ibrahim, A., Faisal, S. and Jamil, N. (2009). Use of basalt in asphalt concrete mixes. Construction and Building Materials, 23(1), pp. 498-506.

[2] Morova, N. (2013). Investigation of usability of basalt fibers in hot mix asphalt concrete. Construction and Building Materials, 47, pp. 175-180.

[3] Zheng, Y., Cai, Y., Zhang, G. and Fang, H. (2014). Fatigue property of basalt fiber-modified asphalt mixture under complicated environment. Journal of Wuhan University of Technology-Mater. Sci. Ed., 29(5), pp. 996-1004.

[4] Gao, C. and Wu, W. (2018). Using ESEM to analyze the microscopic property of basalt fiber reinforced asphalt concrete. International Journal of Pavement Research and Technology, 11(4), pp. 374-380.

[5] Lachance-Tremblay, É., Vaillancourt, M. and Perraton, D. (2016). Evaluation of the impact of recycled glass on asphalt mixture performances. Road Materials and Pavement Design, 17(3), pp. 600-618.

[6] Saltan, M., Öksüz, B. and Uz, V. E. (2015). Use of glass waste as mineral filler in hot mix asphalt. Science and Engineering of Composite Materials, 22(3), pp. 271-277.

[7] Arabani, M. (2011). Effect of glass cullet on the improvement of the dynamic behaviour of asphalt concrete. Construction and Building Materials, 25(3), pp. 1181-1185.

[8] Wang, D. (2015). Simplified analytical approach to predicting asphalt pavement temperature. Journal of Materials in Civil Engineering, 27(12), 04015043.

[9] Ozer, H., Al-Qadi, I. L., Singhvi, P., Bausano, J., Carvalho, R., Li, X. and Gibson, N. (2018). Prediction of pavement fatigue cracking at an accelerated testing section using asphalt mixture performance tests. International Journal of Pavement Engineering, 19(3), pp. 264-278.

[10] Kaur, D. and Tekkedil, D. (2000). Fuzzy expert system for asphalt pavement performance prediction. In Intelligent Transportation Systems, 2000. Proceedings. 2000 IEEE, pp. 428-433.

[11] Sodikov, J. (2005). Cost estimation of highway projects in developing countries: artificial neural network approach. Journal of the Eastern Asia Society for Transportation Studies, 6, pp. 1036-1047.

[12] Tapkın, S., Çevik, A. and Uşar, Ü. (2010). Prediction of Marshall test results for polypropylene modified dense bituminous mixtures using neural networks. Expert Systems with Applications, 37(6), pp. 4660-4670.

[13] ASTM (2004). 3515, Standard Specification for Hot-Mixed, Hot-Laid Bituminous Paving Mixtures. Annual Book of Standards, 4. 
[14]T. Deak and T. Czigany, Chemical Composition and Mechanical Properties of Basalt and Glass Fibers: A Comparison, Textile Research Journal, 79 (7), pp. 645-651, 2009.

[15] ASTM, D. (1989). 1559 (1989)“Test method for resistance of plastic flow of bituminous mixtures using Marshall apparatus". American Society for Testing and Materials, Philadelphia, USA.

[16] AASHTO, T. (2007). Standard method of test for resistance of compacted asphalt mixtures to moisture-induced damage. AASHTO Provisional Standards: Washington, DC, USA.

[17] Al-Qadi, I. L., Yoo, P. J., Elseifi, M. A. and Nelson, S. (2009). Creep behavior of hot-mix asphalt due to heavy vehicular tire loading. Journal of engineering mechanics, 135(11), pp. 1265-12. DOI: 10.1061/(ASCE)07339399(2009)135:11(1265))

[18] Yoder, E. J. and Witczak, M. W. (1975). Principles of pavement design. John Wiley \& Sons.

[19] Ghanei, A., Jafari, F., Khotbehsara, M. M., Mohseni, E., Tang, W., \& Cui, H. (2017). Effect of nano-CuO on engineering and microstructure properties of fibre-reinforced mortars incorporating metakaolin: Experimental and numerical studies. Materials, 10(10), 1215.

[20] Taherkhani, H. (2016). Investigating the properties of asphalt concrete containing glass fibers and nanoclay. Civil Engineering Infrastructures Journal, 49(1), pp. 45-58.

[21] Morova, N. and Terzi, S. (2015). Evaluation of Colemanite Waste as Aggregate Hot Mix Asphalt Concrete. Süleyman Demirel Üniversitesi Fen Bilimleri Enstitüsü Dergisi, 19(2).

[22] Nguyen, M. L., Blanc, J., Kerzreho, J. P. and Hornych, P. (2013). Review of glass fibre grid use for pavement reinforcement and APT experiments at IFSTTAR. Road Materials and Pavement Design, 14(1), pp. 287-308.

[23] Naseri, F., Jafari, F., Mohseni, E., Tang, W., Feizbakhsh, A. and Khatibinia, M. (2017). Experimental observations and SVM-based prediction of properties of polypropylene fibres reinforced self-compacting composites incorporating nano-CuO. Construction and Building Materials, 143, pp. 589-598. DOI: 10.1016/j.conbuildmat.2017.03.124. 